\title{
Assessing the Syrian Population's Knowledge, Attitudes, and Practices Regarding Antibiotic Usage
}

\author{
Nizar Daher ${ }^{1}$ Ahmad Al-Moujahed ${ }^{3}$ \\ ${ }^{1}$ Faculty of Medicine, Department of Internal Medicine, Syrian \\ Private University, Damascus, Syria \\ ${ }^{2}$ Department of Internal Medicine, Hamad Medical Corporation, \\ Doha, Qatar \\ ${ }^{3}$ Department of Ophthalmology, Byers Eye Institute, Stanford \\ School of Medicine, Stanford, California, United States
}

Abdallah Altorkmani ${ }^{1}$ Mhd Amin Alzabibi ${ }^{1} \quad$ Mosa Shibani ${ }^{1} \quad$ Hlma Ismail ${ }^{1}$ Bisher Sawaf ${ }^{2}$

Address for correspondence Mhd Amin Alzabibi, MD, Faculty of Medicine, Syrian Private University, Mazzeh Street, P.O. Box 36822, Damascus, Syria (e-mail: ameenzabibi@gmail.com).

Avicenna J. Med. 2021;3:132-138.

\section{Abstract}

Keywords

- antibiotic use

- antibiotic resistance

- knowledge

- attitude

- practices

- Syria
Background Antibiotic resistance is a serious public health threat that results mainly secondary to antibiotics misuse. The present study aimed to determine the knowledge, attitude, and practice toward antibiotic use among the Syrian population.

Methods This cross-sectional study was conducted at the outpatient clinics of two major hospitals in Damascus, Syria. Applying a random convenience sampling, data were collected in a 1-week period by interviewing participants using a structured questionnaire, which targeted demographics, practice, knowledge, and attitude. Data were used to assess the relationship between the knowledge level and attitudes and demographics.

Results Most respondents had a moderate level of knowledge (187, 74.8\%) and a moderate attitude score $(148,59.2 \%)$. In addition, most respondents $(149,59.6 \%)$ stated that they take antibiotics based on pharmacist advice only and do not complete the full antibiotic course (200, 80\%). A significant association was found between the knowledge level and financial status ( $p$-value $=0.003)$, education level $(p$-value $=0.001)$, and having relatives working in the health care sector ( $p$-value $=$ $0.021)$. In addition, a significant association was found between the attitude and having health insurance.

Conclusion This study provides baseline evidence about the knowledge, attitudes, and practices regarding antibiotics among the Syrian population, that will help in designing targeted interventions to solve the inappropriate use of antibiotics.

\section{Introduction}

Infectious diseases used to be the leading cause of death until the discovery of antibiotics in the last century. ${ }^{1}$ However, antibiotic resistance has emerged as a serious public health problem both in developing and developed countries and currently it is among the top 10 risks threatening our world

published online August 13, 2021
DOI https://doi.org/ $10.1055 / \mathrm{s}-0041-1732815$ ISSN 2231-0770 according to the Global Risk Report 2020 from the World Economic Forum. ${ }^{1,2}$ Antibiotic-resistant infections account for at least 700,000 deaths per year globally and it is estimated that this number will reach 10 million deaths per year by $2050 .^{3}$ These infections lead to long-term morbidity, prolonged stay in the hospitals, higher intensive care unit admissions, septic shock, and therefore high mortality rate. ${ }^{4-6}$

(c) 2021. Syrian American Medical Society.

This is an open access article published by Thieme under the terms of the Creative Commons Attribution License, permitting unrestricted use, distribution, and reproduction so long as the original work is properly cited. (https://creativecommons. org/licenses/by/4.0/).

Thieme Medical and Scientific Publishers Private Limited A-12, Second Floor, Sector -2, Noida-201301, Uttar Pradesh 
In addition, antibiotic resistance place a significant burden on the economy. For instance, the gross domestic product loss attributed to antibiotic resistance in the Middle East and North Africa (MENA) countries, including Syria, has been estimated to reach 159 billion U.S. dollar per year. ${ }^{7}$

Antibiotic resistance occurs naturally, but overuse and misuse of antibiotics significantly accelerates this phenomenon. ${ }^{8}$ This can result from overprescription, empirical use, and prescribing antibiotics to meet patients' demand for quick recovery even if not clinically indicated. ${ }^{9}$ Other reasons include patients treating themselves, nonprescription purchase, not finishing prescribed courses, and inadequate dosage. $^{10-15}$

A new spike in antibiotics usage has been noticed during the coronavirus disease 2019 (COVID-19) era especially for azithromycin. ${ }^{16} \mathrm{~A}$ recent survey showed that antibiotics are the second most prescribed medications, only after acetaminophen, for COVID-19 patients in the United States. ${ }^{17}$ Rising evidence shows a high prevalence of antibiotic resistance in bacterial coinfections in COVID-19 patients, leading to a higher mortality rate in those patients. ${ }^{18}$ One study showed that over 90\% of COVID-19 patients received empirical antibiotics although less than $10 \%$ were confirmed to have a secondary infection..$^{18}$ Many individuals are taking antibiotics in an attempt to protect themselves from the virus by self-medicating, especially in developing countries where antibiotics can be obtained without a prescription. ${ }^{19,20}$

In Syria, although there are regulations prohibiting the sale of antibiotics without a prescription, most pharmacies do not adhere to them. A study in Aleppo, Syria, reported that $85.5 \%$ of the pharmacists in the city would give the patient antibiotics without a prescription. ${ }^{21-23}$ There is a paucity of rigorous data in Syria regarding the burden of antibiotic resistance. Data from neighboring countries and Europe show significantly higher rates of this phenomenon among refugees compared with the locals. ${ }^{23,24}$

The knowledge, attitude, and practice (KAP) of the population regarding antibiotics has been evaluated in many countries as a first step toward taking necessary measures to address antibiotic resistance. ${ }^{8,25,26}$ Many countries have also led national campaigns to change the public's misconceptions related to antibiotics usage. ${ }^{14,27}$ However, in Syria, to our knowledge only one study was conducted in 2010 in the Kalamoon region to assess the KAP of the population and it found a high prevalence of antibiotics consumption and a lack of knowledge on the hazards of antibiotics use among the participants. ${ }^{28}$ In this study, we aimed to assess the KAP toward antibiotics use among the Syrian community during the time of two major crises affecting the country: COVID-19 and the war, as well as to identify the demographic characteristics affecting the population awareness. In addition, we wanted to explore the public views on the doctors' habits and the patient-doctor relationship when prescribing antibiotics.

\section{Methods}

\section{Study Design, Setting, and Participants}

A cross-sectional study was conducted on the patients attending the outpatient clinics at two major hospitals in Damascus, Syria (Damascus Hospital and Ibn Al Nafees Hospital) which were among the few hospitals that did not close their clinics during the COVID-19 quarantine. Patients were interviewed using a structured questionnaire adapted from a similar previous study and modified to suit our population. ${ }^{25} \mathrm{~A}$ pilot study was conducted on 30 participants to ensure the validity and reliability of the questionnaire. The sample included 250 out of 624 of patient who came to the clinics between May 25, 2020, and May 31, 2020, from 8 a.m. till 4 p.m. who met the inclusion criteria ${ }^{1}: 18$ years old and above, ${ }^{2}$ understand the term "antibiotic" and its equivalents, ${ }^{3}$ have been living in Syria for the past 5 years, ${ }^{4}$ were cooperative, and completed the questionnaire. The questionnaire consisted of five sections ${ }^{1}$ : demographics, which contained 14 questions, ${ }^{2}$ practice section, which included 5 multiple-choice questions, ${ }^{3}$ knowledge section made out of 15 statements, and ${ }^{4}$ attitude section with 9 statements, $^{5}$ 1 question regarding the use of antibiotics during COVID- 19 . All of the responses were recorded anonymously and a written consent form was obtained before filling the questionnaire from all participants.

\section{Statistical Analysis}

Statistical Package for Social Sciences (SPSS) version 25.0 was used for data analysis and data reported as frequencies, and percentages (for categorical variables). A scoring system was used to analyze the participants' knowledge and attitude. The correct answer was given " 1 " point and the wrong or uncertain answers were given " 0 "; then the scores regarding knowledge were classified into poor $(0-5 / 15)$, moderate (6-10/15), and good (11-15/15) while the attitudes scores were divided into poor $(0-3 / 9)$, moderate (4-6/9), and good (7-9/9). The mean frequencies and percentages of correct answers were calculated, and the chi-square test was applied to assess the relationship between the knowledge level and attitudes and demographics. The statistical significance was set at $p$-value $<0.05$.

\section{Results}

\section{Sociodemographic Characteristics of Participants}

Out of 297 patients, 250 answered all questioned during the interview with a response rate of $84 \%$. As illustrated in - Table 1, the sample consisted of 149 (59.6\%) males and 101 (40.4\%) females. The mean age of the participants was 41.07 $( \pm 14.9)$ years with the age group 18 to 30 being the most common (28.4\%). Only 46 (18.4\%) participants had health insurance. Thirty-eight (33.2\%) and 45 (18.0\%) of the participants were in "below the average" or "bad" financial status, respectively. More than half of the included participants (145, $58.0 \%$ ) have changed their residence as a result of the war. 
Table 1 Participants' characteristics $(n=250)$

\begin{tabular}{|c|c|}
\hline Variables & $N(\%)$ \\
\hline \multicolumn{2}{|l|}{ Age $(y)$} \\
\hline $18-30$ & $71(28.4)$ \\
\hline $31-40$ & $63(25.2)$ \\
\hline $41-50$ & $51(20.4)$ \\
\hline $51-60$ & $34(13.6)$ \\
\hline$>60$ & $31(12.4)$ \\
\hline \multicolumn{2}{|l|}{ Gender } \\
\hline Male & $149(59.6)$ \\
\hline Female & $101(40.4)$ \\
\hline \multicolumn{2}{|l|}{ Marital status } \\
\hline Single & $53(21.2)$ \\
\hline In a relationship & $1(0.4)$ \\
\hline Married & $196(78.4)$ \\
\hline \multicolumn{2}{|c|}{ Do you have health insurance? } \\
\hline No & $204(81.6)$ \\
\hline Yes & $46(18.4)$ \\
\hline \multicolumn{2}{|l|}{ Current residence } \\
\hline City & $114(45.6)$ \\
\hline Rural & $136(54.4)$ \\
\hline \multicolumn{2}{|c|}{ Did you change your place of residence due to the war? } \\
\hline No & $105(42.0)$ \\
\hline Yes & $145(58.0)$ \\
\hline \multicolumn{2}{|l|}{ Financial status } \\
\hline Bad & $45(18.0)$ \\
\hline Below average & $83(33.2)$ \\
\hline Average & $107(42.8)$ \\
\hline Good & $15(6.0)$ \\
\hline Excellent & $0(0.0)$ \\
\hline \multicolumn{2}{|c|}{ What is your highest education level? } \\
\hline None & $14(5.6)$ \\
\hline Elementary & $69(27.6)$ \\
\hline Secondary & $81(32.4)$ \\
\hline High school & $30(12)$ \\
\hline University & $51(20.4)$ \\
\hline Post-university & $5(2.0)$ \\
\hline \multicolumn{2}{|c|}{ Do you have relatives who work in the health sector? } \\
\hline No & $164(65.6)$ \\
\hline Yes & $86(34.4)$ \\
\hline
\end{tabular}

\section{Practice Habits}

When asked about the way they get their antibiotics, most of the participants $(149,59.6 \%)$ chose "pharmacist's advice," whereas only 64 participants (25.6\%) chose "doctor's prescription." The majority of the participants (196, 78.4\%) stated that they have used antibiotics in the last 6 months to prevent or treat COVID-19 infection. Among those, the most commonly used antibiotics were azithromycin (61.1\%), augmentin (amoxicillin-clavulanic acid) (53.3\%), ceftriaxone (52.6\%), and metronidazole (39.8\%) (-Fig. 1). One hundred two $(40.8 \%)$ participants agreed that they rarely consult a doctor when they are sick. The main reason for not consulting a physician was financial burden (115, 52.5\%). Almost half of the participants $(117,46.8 \%)$ wait 1 to 2 days from the appearance of symptoms, for which they think antibiotics are required, before starting using them, and 56 (22.4\%) start directly ( - Table 2 ).

\section{Knowledge Regarding Antibiotics}

Most of the respondents $(187,74.8 \%$ ) had a moderate level of knowledge, while $42(16.8 \%)$ had a poor knowledge level, and only 21 (8.4\%) were well knowledgeable.

Note that 134 (53.6\%) participants agreed that antibiotics are medications that kill bacteria. However, only 61 (24.4\%) participants were aware that antibiotics have no effect on viruses and 90 (36.0\%) were unsure. The most common misconception among the participants was that antibiotics reduce pain and inflammation (236, 94.4\%). Fifty-three (21.2\%) of the participants recognized penicillin as an antibacterial agent, whereas 120 (48\%) were unsure. On the other hand, the majority $(213,85.2 \%)$ and 185 (74\%) acknowledged that Panadol (paracetamol; acetaminophen) and brufen (ibuprofen), respectively, are not antibiotics. Although the majority of the participants (202, 80.8\%) knew that antibiotics misuse leads to antibiotic resistance, a considerable proportion of them $(172,68.8 \%)$ considered that they would stop taking the full course of antibiotics if their symptoms improved (Supplementary Table S1, online only).

\section{Attitude Regarding Antibiotic Consumption}

Most participants $(148,59.2 \%)$ showed a moderate attitude score, followed by poor $(67,26.8 \%)$ and good attitude (35, $14 \%)$. Most of the respondents $(200,80 \%)$ stated that they would stop taking antibiotics once they feel better. One hundred and fifty-eight (63.2\%) participants disagreed with the statement that taking antibiotics accelerate the healing from cold. However, 90 (36\%) of them stated that they expect their doctor to prescribe antibiotics when they experience symptoms of the common cold. A substantial number of the study population $(179,71.9 \%)$ responded that they stock antibiotics in their houses, and 214 (85.6\%) use the remaining antibiotics if they get the same illness again (Supplementary Table S2, online only).

\section{The Association between Sociodemographic Variables and Knowledge and Attitude Scores}

No relationship was observed between the level of knowledge and age, gender, place of residence, or having health insurance. However, a significant association was found between the financial status ( $4.4 \%$ vs. $33.3 \%$, chi-square $=20.227, p$-value $=0.003)$, education level $(7.1 \%$ vs. $20 \%$, chi-square $=29.054, p$-value $=0.001)$, and having relatives work in the health sector ( $4.9 \%$ vs. $15.1 \%$, chi-square $=7.734$, $p$-value $=0.021$ ) and the knowledge level. The level of attitude was significantly associated with educational level 


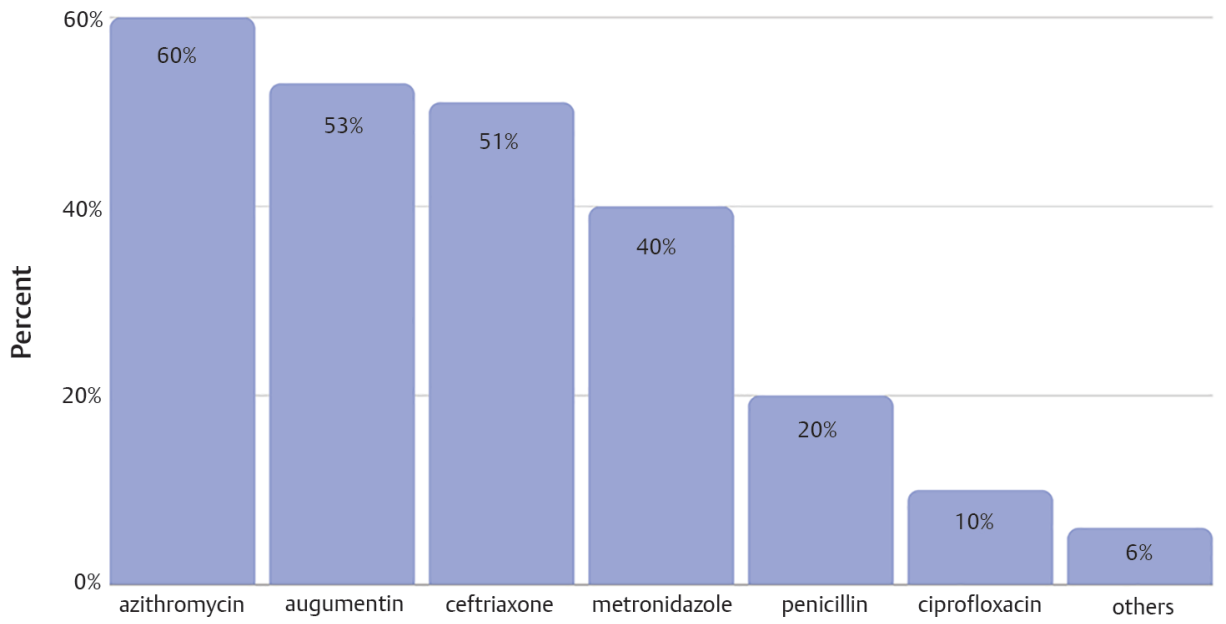

Fig. 1 What were the antibiotics you used in the last 6 months? (Choose all that apply).

Table 2 Questions regarding practice habits

\begin{tabular}{|c|c|c|}
\hline Question & Answer & $N(\%)$ \\
\hline \multirow{5}{*}{$\begin{array}{c}1 \text { - How do you get } \\
\text { your antibiotics? }\end{array}$} & Doctor’s prescription & $64(25.6)$ \\
\hline & $\begin{array}{l}\text { Without a doctor's } \\
\text { prescription }\end{array}$ & $3(1.2)$ \\
\hline & Pharmacist's advice & $149(59.6)$ \\
\hline & $\begin{array}{l}\text { Nonmedical person's } \\
\text { advice }\end{array}$ & $7(2.8)$ \\
\hline & Personal choice & $27(10.8)$ \\
\hline \multirow{8}{*}{$\begin{array}{l}2 \text { - What is the reason } \\
\text { for using antibiot- } \\
\text { ics? (choose all that } \\
\text { apply) }\end{array}$} & Fever & $30(12)$ \\
\hline & Cold & $68(27.2)$ \\
\hline & $\begin{array}{l}\text { Pain and } \\
\text { inflammation }\end{array}$ & $216(86.4)$ \\
\hline & Urinary tract infection & $56(22.4)$ \\
\hline & Skin wound & $76(30.4)$ \\
\hline & $\begin{array}{l}\text { Teeth and gum } \\
\text { inflammation }\end{array}$ & $109(43.6)$ \\
\hline & Ear inflammation & $100(40)$ \\
\hline & Diarrhea & $8(3.2)$ \\
\hline \multirow{4}{*}{$\begin{array}{l}3 \text { - Do you consult a } \\
\text { doctor when you're } \\
\text { sick? }\end{array}$} & Never & $3(1.2)$ \\
\hline & Rarely & $102(40.8)$ \\
\hline & Sometimes & $110(44.0)$ \\
\hline & Always & $35(14.0)$ \\
\hline \multirow{5}{*}{$\begin{array}{l}4 \text { - Reason for not } \\
\text { always consulting a } \\
\text { doctor }\end{array}$} & Money & $115(52.5)$ \\
\hline & $\begin{array}{l}\text { Unavailability of } \\
\text { doctors }\end{array}$ & $12(5.5)$ \\
\hline & Scared & $8(3.7)$ \\
\hline & No need for a doctor & $71(32.4)$ \\
\hline & No time & $13(5.9)$ \\
\hline \multirow{4}{*}{$\begin{array}{l}5 \text { - Waiting time } \\
\text { before starting an } \\
\text { antibiotic? }\end{array}$} & Directly & $56(22.4)$ \\
\hline & $1-2 d$ & $117(46.8)$ \\
\hline & $3-4 d$ & 49 (19.6) \\
\hline & $>4 d$ & $28(11.2)$ \\
\hline
\end{tabular}

(7.2\% vs. $40 \%$, chi-square $=24.052, p$-value $=0.007)$ and having health insurance $(11.3 \%$ vs. $26.1 \%$, chi-square $=9.890$, $p$-value $=0.007)$. No significant associations were found between attitude and the other variables (Supplementary Tables S3 and S4, online only).

\section{Discussion}

This study highlights several misconceptions and improper practices related to antibiotic usage in Syria during the COVID-19 era. Our results show that most of the population get their antibiotics directly from the pharmacies. These results are not surprising especially that, as previous studies have shown, about a quarter of pharmacists considered themselves qualified to prescribe medication without consulting a doctor, and $85 \%$ sold antibiotics without a prescription. ${ }^{21,22}$ This clearly indicates that the legislations that regulate the purchasing of antibiotics are neglected and proposes questions about the governing agency's role in limiting antibiotics misuse among the Syrian community. Similar results were reported in other MENA countries. ${ }^{14,25,29}$

Our study revealed a high rate of self-medication in response to the COVID-19 pandemic using antibiotics. Self-medication is a concerning globally prevalent practice, ${ }^{30-33}$ which should be controlled appropriately, mainly in low- and middle-income countries that have low educational levels and weak health care systems, especially during the COVID-19 pandemic. ${ }^{34}$ The most common self-medicated antibiotics used among patients in our sample were azithromycin followed by augmentin (amoxicillin-clavulanic acid), unlike a similar study in Nigeria where augmentin (amoxicillin-clavulanic acid) came first. ${ }^{35}$ Interestingly, a recent study in the U.S. reported a shortage in the supply of azithromycin after a high consumption rate due to COVID-19. ${ }^{36}$ Two previous studies in Syria have reported that $35 \%$ to $43 \%$ of the isolated bacteria are resistant to augmentin (amoxicillin-clavulanic acid). ${ }^{37,38}$

Mouhieddine et al reported that $27.5 \%$ of the Lebanese population always consult a doctor when sick. ${ }^{25}$ However, 
only $14 \%$ of our study population always consider consulting a physician. Financial burden was the main reason for not visiting a doctor in our sample, whereas the assumption of no need for a doctor was the main reason in the Lebanese population..$^{25}$ The conflict in Syria has caused an inconceivable degree of devastation and destruction to the Syrian population and their economy, making the exchange rate continuously fluctuating which made it difficult to define an objective cutoff regarding the financial status, that is why we chose to make the question subjective. Also, a shortage in access to health care, education, housing, and food have worsened the consequences of the conflict and forced millions of people into unemployment and indigence. ${ }^{39}$

The majority of our study sample showed a moderate level of knowledge regarding antibiotics and their usage. This is in alignment with multiple other studies that were conducted in Lebanon, Qatar, Oman, and Syria. ${ }^{25,28,40,41}$ However, this is less than a study by Abu Taha et al who reported that more than half of the participants in Palestine, which also suffers from war and bad economic status, showed a good level of knowledge. ${ }^{42}$ Although it is well known that antibiotics do not affect viruses, one of the most common misconceptions among different populations in most studies, including this one, is that antibiotics can be used to treat viral infections. ${ }^{25,26,40,43-45}$ It is of great importance to correct this misconception, which will reflect positively on the way people use drugs and limit self-medication with antibiotics. In a previous study in the Kalamoon region in Syria in 2010, Barah and Gonçalves reported that only $10 \%$ of participants were aware that antibiotics misuse would lead to antibiotic resistance. ${ }^{28}$ However, in our study, this percentage increased dramatically to reach $80.8 \%$, which is probably due to differences in the socioeconomic characteristics of the two samples or it may suggest an increased level of awareness about the risk of antibiotic resistance. Similar level of knowledge on this topic was reported in other studies in the MENA regi ons. ${ }^{26,40,42,43}$ Except for two studies in Jordan and Egypt where 70 and $43 \%$ of the participants, respectively, never heard of the term "antibiotic resistance." ${ }^{45,46}$

The World Health Organization and other global health organizations advise against stopping antibiotics early before the full treatment course is completed because this increases the rate of the development of antibiotic resistance. ${ }^{3}$ However, the results of many studies, including ours, indicate that most participants lack the knowledge on this topic, as $68.8 \%$ of them believe that stopping the drug is the right thing to do. ${ }^{25,40,41}$

Most participants in our study had a moderate attitude score regarding antibiotics consumption similar to studies in Lebanon and Oman, ${ }^{25,41}$ but less than a study in the Palestinian population. ${ }^{42}$ In addition, $36 \%$ of our sample expected their doctor to prescribe antibiotics when they experience flu-like symptoms, which is less than similar studies in Lebanon and Jordan. ${ }^{25,29}$ This expectation may encourage some doctors to resort to wrongly prescribing antibiotics to appease their patients and maintain a good relationship with them. This physicians' behavior can have numerous negative consequences on the individual and population health. ${ }^{47,48}$
About a third of the study participants reported that they would take antibiotics to speed up the healing process when they have a cold. These results indicate a better behavior regarding this issue than other studies in Ethiopia, Lebanon, Qatar, Kuwait, and Palestine where 83.1, 52.3, 40.1, 43.4 , and $65.1 \%$ of the participants, respectively, answered that they use antibiotics to speed up the healing process of cold-like symptoms. ${ }^{25,26,40-42}$ In addition, our study and other similar studies showed the tendency of people to store antibiotics at home for future use. ${ }^{25,26,29,40}$ These stored antibiotics will be used for self-medication if the patient develops similar symptoms in the future as indicated by the participant's response in our study and other similar studies. ${ }^{25,41,42,46}$

As expected and similar to other similar studies in other countries, ${ }^{25,49,50}$ our study revealed that lower education and financial status are associated with lower knowledge about this topic. This has probably significantly worsened in Syria during the past decade due to the effect of the war on education and the economy. ${ }^{50} \mathrm{We}$ also found an association between the level of knowledge and having relatives who work in the health sector, which shows the effect of health care workers on educating their social circles. Although public hospitals in Syria provide proved some free services like consulting, many other services are paid at low cost compared with the private hospitals like radiography, laboratory testing, and surgeries, making having an insurance a necessity. We found a significant association between having a health insurance and attitude, but not knowledge. This suggests that financial hardship is the main reason preventing many individuals from seeking proper health care that starts with doctors who usually prescribe unnecessary antibiotics less commonly than pharmacist. In fact, more than half of the participants (52.5\%) stated that lack of money is the reason for not always consulting a doctor when they are sick and most of them seek pharmacists' advice directly for financial reasons. Although the law in Syria requires a doctor's prescription to dispense antibiotics, a prior study in Syria showed that $100 \%$ of the pharmacists who participated in the study dispense medications, including antibiotics, without prescription and will most probably continue to do so. ${ }^{21}$ This phenomenon has been also observed in other countries in the region, such as Lebanon, Jordan, and Qatar. ${ }^{25,40,46}$

Overall, this suggests that national educational campaigns about this issue, which have been effective in other countries, ${ }^{49,51,52}$ should target not only patients, but also doctors and pharmacists. In addition, it is important to activate the laws that prevent pharmacies from selling an antibiotic without a prescription, and to set new guidelines for doctors regarding antibiotics prescription. Finally, providing patients who have financial difficulties with a health insurance may help in reducing self-medication and seeking proper medical care.

\section{Limitations}

This research is subject to several limitations that could be addressed in future research. Our data might not be representative due to three reasons: (1) a small sample size which 
was caused mainly due to COVID-19 restrictions which affected the number of people attending the clinics and lack of collaboration due to fear of catching COVID-19. (2) The use of convenience sampling due to lack of funding. (3) Selection bias caused by inundating the sample with low and average financial status participants, caused by the fact that the two selected hospitals treat people free of charge, even though they are considered the largest hospitals in the city. Regarding the questionnaire, two questions were subject to recall bias, and the practice section contained three subjective questions.

\section{Conclusion}

In conclusion, the majority of the participants in our study had a moderate level of knowledge and attitudes toward antibiotic use. Unfortunately, many participants were using antibiotics for the wrong reasons and in a wrong way for many reasons, including low financial and educational levels. We recommend: (1) reactivation and enforcing the laws that prohibit pharmacist from selling drugs without prescription with high penalties, (2) establishing strict laws to regulate prescribing antibiotics, and (3) conducting awareness campaigns targeting particularly individuals of low educational and financial status. This study provides helpful data for later work aiming to target the problem of antibiotic misuse and resistance in Syria.

\section{Ethical Considerations}

The study protocol was reviewed and approved by the Syrian Private University's Institutional Review Board (IRB), and the ethical committees in the two hospitals.

Conflict of Interest

None declared.

\section{References}

1 Franco E, ed. The Global Risks Report 2020. Cologny, Switzerland: World Economic Forum; 2020

2 Vilá JJ. Update on antibacterial resistance in low-income countries: factors favoring the emergence of resistance. Open Infect Dis J 2010;4:38-54

3 Nations ICGoARJRtts-gotU, No time to Wait: Securing the Future from Drug-Resistant Infections. Geneva, Switzerland: World Health Organization; 2019

4 World HealthOrganization, Antimicrobial Resistance: Global Report on Surveillance. Geneva, Switzerland: World Health Organization; 2014

5 Coast J, Smith RD, Millar MR. Superbugs: should antimicrobial resistance be included as a cost in economic evaluation? Health Econ 1996;5(3):217-226

6 World Health Organization \%J World Health Day A. Antimicrobial Resistance: No Action Today, No Cure Tomorrow. Geneva, Switzerland: World Health Organization; 2011

7 Taylor J, Hafner M, Yerushalmi E, et al. Estimating the Economic Costs of Antimicrobial Resistance: Model and Results. Santa Monica, CA: RAND Corporation; 2014

8 World Health Organization. Antibiotic Resistance: Multi-Country Public Awareness Survey. Geneva, Switzerland: World Health Organization; 2015
9 McNulty CA, Boyle P, Nichols T, Clappison P, Davey P. The public's attitudes to and compliance with antibiotics. J Antimicrob Chemother 2007;60(Suppl 1) :i63-i68

10 Van Duong D, Binns CW, Van Le T. Availability of antibiotics as over-the-counter drugs in pharmacies: a threat to public health in Vietnam. Trop Med Int Health 1997;2(12):1133-1139

11 Yagupsky P. Selection of antibiotic-resistant pathogens in the community. Pediatr Infect Dis J 2006;25(10):974-976

12 Michael CA, Dominey-Howes D, Labbate M. The antimicrobial resistance crisis: causes, consequences, and management. Front Public Health 2014;2:145

13 Pechère JC. Patients' interviews and misuse of antibiotics. Clin Infect Dis 2001;33(Suppl 3):S170-S173

14 Grigoryan L, Haaijer-Ruskamp FM, Burgerhof JGM, et al. Self-medication with antimicrobial drugs in Europe. Emerg Infect Dis 2006;12(3):452-459

15 Gonzales R, Steiner JF, Sande MA. Antibiotic prescribing for adults with colds, upper respiratory tract infections, and bronchitis by ambulatory care physicians. JAMA 1997;278(11):901-904

16 Reardon S. Antibiotic treatment for COVID-19 complications could fuel resistant bacteria. Science 2020. doi: 10.1126/science.abc2995

17 Franki R. Survey: Hydroxychloroquine use fairly common in COVID-19 MDedge.com: MDedge 2020. Available from: https://www.mdedge.com/hematology-oncology/article/221494/coronavirus-updates/survey-hydroxychloroquine-use-fairly-common. Accessed December 10, 2020

18 Lai CC, Shih TP, Ko WC, Tang HJ, Hsueh PR. Severe acute respiratory syndrome coronavirus 2 (SARS-CoV-2) and coronavirus disease-2019 (COVID-19): the epidemic and the challenges. Int J Antimicrob Agents 2020;55(3):105924

19 Usman M, Farooq M, Hanna K. Environmental side effects of the injudicious use of antimicrobials in the era of COVID-19. Sci Total Environ 2020;745:141053

20 Jacobs TG, Robertson J, van den Ham HA, Iwamoto K, Bak Pedersen H, Mantel-Teeuwisse AK. Assessing the impact of law enforcement to reduce over-the-counter (OTC) sales of antibiotics in low- and middle-income countries; a systematic literature review. BMC Health Serv Res 2019;19(1):536

21 Bahnassi A. A qualitative analysis of pharmacists' attitudes and practices regarding the sale of antibiotics without prescription in Syria. J Taibah Univ Med Sci 2015;10(2):227-233

22 Mansour O, Al-Kayali R. Community pharmacists' role in controlling bacterial antibiotic resistance in Aleppo, Syria. Iran J Pharm Res 2017;16(4):1612-1620

23 Jakovljevic M, Al Ahdab S, Jurisevic M, Mouselli S. Antibiotic resistance in Syria: a local problem turns into a global threat. Front Public Health 2018;6:212

24 Nellums LB, Thompson H, Holmes A, et al. Antimicrobial resistance among migrants in Europe: a systematic review and meta-analysis. Lancet Infect Dis 2018;18(7):796-811

25 Mouhieddine TH, Olleik Z, Itani MM, et al. Assessing the Lebanese population for their knowledge, attitudes and practices of antibiotic usage. J Infect Public Health 2015;8(1):20-31

26 Awad AI, Aboud EAJ. Knowledge, attitude and practice towards antibiotic use among the public in Kuwait. PLoS One 2015;10(2):e0117910

27 Chaintarli K, Ingle SM, Bhattacharya A, Ashiru-Oredope D, Oliver I, Gobin M. Impact of a United Kingdom-wide campaign to tackle antimicrobial resistance on self-reported knowledge and behaviour change. BMC Public Health 2016;16(1):393

28 Barah F, Gonçalves V. Antibiotic use and knowledge in the community in Kalamoon, Syrian Arab Republic: a cross-sectional study. East Mediterr Health J 2010;16(5):516-521

29 Darwish DA, Abdelmalek S, Abu Dayyih W, Hamadi S. Awareness of antibiotic use and antimicrobial resistance in the Iraqi community in Jordan. J Infect Dev Ctries 2014;8(5):616-623 
30 Ocan M, Obuku EA, Bwanga F, et al. Household antimicrobial self-medication: a systematic review and meta-analysis of the burden, risk factors and outcomes in developing countries. BMC Public Health 2015;15(1):742

31 Grigoryan L, Haaijer-Ruskamp FM, Burgerhof JGM, et al. Self-medication with antimicrobial drugs in Europe. Emerg Infect Dis 2006;12(3):452-459

32 Kassie AD, Bifftu BB, Mekonnen HS. Self-medication practice and associated factors among adult household members in Meket district, Northeast Ethiopia, 2017. BMC Pharmacol Toxicol 2018;19(1):15

33 Sweileh PW, Self-Medication and Over-the-Counter Practices: A Study in Palestine. J Al-Aqsa Unv; $2004 ; 8$

34 Al-Worafi YM, Chapter 29 - Drug safety in Yemen. In: Al-Worafi Y, ed. Drug Safety in Developing Countries. Fujairah, UAE: Academic Press; 2020 391- 405

35 Chukwu EE, Oladele DA, Awoderu OB, et al. A national survey of public awareness of antimicrobial resistance in Nigeria. Antimicrob Resist Infect Control 2020;9(1):72

36 Badreldin HA, Atallah B. Global drug shortages due to COVID-19: impact on patient care and mitigation strategies. Res Social Adm Pharm 2021;17(1):1946-1949

37 Abbara A, Rawson TM, Karah N, et al. A summary and appraisal of existing evidence of antimicrobial resistance in the Syrian conflict. Int J Infect Dis 2018;75:26-33

38 Al-Assil B, Mahfoud M, Hamzeh AR. First report on class 1 integrons and Trimethoprim-resistance genes from dfrA group in uropathogenic E. coli (UPEC) from the Aleppo area in Syria. Mob Genet Elements 2013;3(3):e25204

39 WorldBank, The Toll of War: The Economic and Social Consequences of the Conflict in Syria. Washington, D.C.: World Bank; 2017

40 Moienzadeh A, Massoud T, Black E. Evaluation of the general public's knowledge, views and practices relating to appropriate antibiotic use in Qatar. Int J Pharm Pract 2017;25(2):133-139

41 Jose J, Jimmy B, Alsabahi AG. Al Sabei GA. A study assessing public knowledge, belief and behavior of antibiotic use in an Omani population. Oman Med J 2013;28(5):324-330

42 Abu Taha A, Abu-Zaydeh AH, Ardah RA, et al. Public knowledge and attitudes regarding the use of antibiotics and resistance: findings from a cross-sectional study among Palestinian adults. Zoonoses Public Health 2016;63(6):449-457
43 Jifar A, Ayele Y. Assessment of knowledge, attitude, and practice toward antibiotic use among Harar city and its surrounding community, Eastern Ethiopia. Interdiscip Perspect Infect Dis 2018;2018:8492740

44 Irawati L, Alrasheedy AA, Hassali MA, Saleem F. Low-income community knowledge, attitudes and perceptions regarding antibiotics and antibiotic resistance in Jelutong District, Penang, Malaysia: a qualitative study. BMC Public Health 2019;19(1):1292

45 El-Hawy RM, Ashmawy MI, Kamal MM, et al. Studying the knowledge, attitude and practice of antibiotic misuse among Alexandria population. Eur J Hosp Pharm Sci Pract 2017;24(6):349-354

46 Yusef D, Babaa AI, Bashaireh AZ, et al. Knowledge, practices \& attitude toward antibiotics use and bacterial resistance in Jordan: a cross-sectional study. Infect Dis Health 2018;23(1):33-40

47 Tourmousoglou CE, Yiannakopoulou ECh, Kalapothaki V. Bramis J, St Papadopoulos J. Adherence to guidelines for antibiotic prophylaxis in general surgery: a critical appraisal. J Antimicrob Chemother 2008;61(1):214-218

48 Al-Momany NH, Al-Bakri AG, Makahleh ZM, Wazaify MM. Adherence to international antimicrobial prophylaxis guidelines in cardiac surgery: a Jordanian study demonstrates need for quality improvement. J Manag Care Pharm 2009;15(3):262-271

49 Kim SS, Moon S, Kim EJ. Public knowledge and attitudes regarding antibiotic use in South Korea. J Korean Acad Nurs 2011;41(6):742-749

50 Elsafti AM, van Berlaer G, Al Safadi M, et al. Children in the Syrian civil war: the familial, educational, and public health impact of ongoing violence. Disaster Med Public Health Prep 2016;10(6):874-882

51 Goossens H, Guillemot D, Ferech M, et al. National campaigns to improve antibiotic use. Eur J Clin Pharmacol 2006;62(5):373-379

52 Huttner B, Goossens H, Verheij T, Harbarth S; CHAMP consortium. Characteristics and outcomes of public campaigns aimed at improving the use of antibiotics in outpatients in high-income countries. Lancet Infect Dis 2010;10(1):17-31 